\title{
Immediate Infusional Reactions to Imunobiological Drugs: Experience of Procedures in an Infusional Center
}

\author{
Patricia A Araujo MD*, Iara Fernandes MD, Jaqueline Morais MD and Marco A Araujo MD \\ Santhè Assisted Treatment Clinic, Brazil
}

Submission: May 02, 2017; Published: MAY 24, 2017

"Corresponding author: Patricia A Araujo, Santhè Assisted Treatment Clinic, Yvon Magalhães Pinto Street 173 Zip Code 30350560 Belo Horizonte Minas Gerais, Brazil, Email: saudesanthe@hotmail. com

\begin{abstract}
Recently, many drugs are used in Dermatology, Rheumatology and Gastroenterology and many are the routes of application. The aim of this article is to analyse the immediate infusional reactions that happen during or in the 30 minutes following the infusional procedure. Abatacept, Adalimumab, Etanercept and Ustekinumab were the imunobiological drugs used in a Infusional Center, located in Belo Horizonte, Minas Gerais, during one year, for the treatment of dermatological, reumatological and gastroenterological diseases. A retrospective study has been done and the informations were withdrawed from patients' files. Secrecy was mantained as only names' inicials were used.
\end{abstract}

Keywords: Immediate infusional reactions; Infusional center; Immunobiological drugs; Imunomediated diseases

\section{Introduction}

Nowadays, several are the immunobiological drugs and many are the application routes. So, in dermatology, we have Ustequinumab [1] Infliximab [2] Etanercept [3], and Adalimumab [4,5] all of them approved of by FDA for treatment of psoriasis and arthritis. In rheumathology, imunobiologics are used in the treatment of reumathoid arthritis [6], juvenil arthritis, ankylosing spondylitis [7], lupus [8]. Imunobiologics are also used in Gastroentherology [9].

Immunobiological drugs era used in the treatment of diseases like psoriasis, psoriatic arthritis, reumathoid arthritis, ankylosing spondylitis, lúpus, Crohn's disease, ulcerative retocolitis. Their route of application can be endovenous or subcutaneous. At the beginning, infusions were done in oncologic clinics and side effects related to the drugs were described in oncologic papers [10]. But patients using immunobiologicals are more predisponed to infections [11]. And the oncologic patients, because of the medicines they use, have a higher risk of contracting infections, which can be disseminated to patients in use of immunobiological drugs. Furthermore, patients with benign diseases and sometimes emotionally shaken, have a fear of having the same side effects of oncologic treatments, as hair loss [12], that can be seen in the patient besides them. That was the beginning of the Infusional Centers for the use of immunobiological drugs in imunnomediated diseases.

\section{Methods}

A previous study demonstrated the side effects that had happened during or 30 minutes after the endovenous application of some immunobiologicals, in a Infusional Center in Brazil [13]. The aim of this article was to demonstrate, during a period of one year, the side effects we could see in a Infusional Center, located in Belo Horizonte, during endovenous or subcutaneous application of immunobiological drugs.

From November 2014 to March 2016, data were collected from patient's filles, preserving their privacy. Only the name's initial letters were used. Patients who received Infliximab (Endovenous route) Abatacept (by endovenous route), Etanercept (subcutaneous route), Adalimumab (subcutaneous route) were questionned about side effects during or 30 minutes after receiving these imunobiological drugs.

The drug used, estimated dose and indication were determined by the patient's doctor. Temperature, blood pressure and heart frequency were measured in all patients, following the clinic's protocol.

The patients were questionned about signs of infection, what contra indicated the infusion.

i. Infliximab was applied via endovenous, $24 \mathrm{dpm}$ (drops per minute) 
ii. Abatacept was applied endovenous, 40 drops per minute

iii. Etanercept and Adalimumab were applied subcutaneous

All the patients who were submitted to an endovenous route of application received pre infusional medication, like Acetaminofen and anti histamine drugs before infusion; patients answered a questionnaire in which doctors could detect any kind of infection or other signs or symptoms which contra indicated infusion. Temperature, blood pressure and heart frequency were monitored each 15 minutes, by the nurse or by the doctor. The patient was also questionned about side effects during or 30 minutes later the infusion. For standardization, we rouped the side effects according to systems. The adopted classification was the following: angioedema, cutaneous, gastrointestinal, hemodynamic, musculoskeletal, neurologic, respiratory or mixed (when there was multissystemic envolvement).

The classification concerning the severity of the reaction was based in the Common Terminology Criteria for Adverse Events [14].

A. Mild reaction: Mild and transitory reaction, when the interruption is not indicated

B. Mild moderate reaction: when the interruption is indicated, but with immediate response to a syntomatic treatment

C. Moderate reaction: Immediate response to syntomatic medication, recurrence after inicial response, hospitalization is indicated

D. Serious reaction: Risk of death

E. Very serious reaction: Death

\section{Results}

Infusions: 412
A. Immunobiological Drugs
i. Infliximab 89 infusions
ii. Etanercept 149 infusions
iii. Abatacept 72 infusions
iv. Adalimumab 72 infusions

B. Side Effects

Infliximab

i. Angioedema not detected

ii. Cutaneous not detected

iii. Gastrointestinal not detected
Hemodynamic 21

i. Musculoskeletal not detected

ii. Neurological not detected

iii. Respiratory not detected

iv. mixed not detected

C. Etanercept

i. Angioedema not detected

ii. Cutaneous 2 (bruise)

iii. Gastrointestinal not detected

iv. Hemodynamic 1( Bradycardia)

v. Musculoskeletal not detected

vi. Neurological not detected

vii. Respiratory not detected

viii. mixed not detected

a. Adalimumabe

i. Angioedema not detected

ii. Cutaneous not detected

iii. Gastrointestinal 1 Diarrhea

iv. Hemodynamic not detected

v. Musculoskeletal not detected

vi. Neurological not detected

vii. Respiratory not detected

viii. mixed not detected

b. Abatacepte

i. Angioedema not detected

ii. Cutaneous not detected

iii. Gastrointestinal not detected

iv. Hemodynamic 11 (higher blood pressure during the infusion)

v. Musculoskeletal not detected

vi. Neurological not detected

vii. Respiratory not detected

viii. mixed not detected

\section{Discussion}

Infliximab is a monoclonal antibody (anti TNF alfa) [15] According to the literature the majority of side effects related to the drug was mild to moderate and included: dyspnoea, urticaria and headache. 
Etanercepte is a humanized fusion protein. It is a TNFtransmembrane competitive blocker. According to the literature, the most common side affected is a reaction in the site of injection. Adalimumab is a human monoclonal antibody. The side effect more frequently seen is the reaction in the site of injection. Increased infections, mainly airways infections and genitourinary infections. Rare cases of anaphylaxis have been reported, as well as thrombocytopenia. Adalimumab may induce FAN and anti DNA formation and Lupus like syndrome.

Abatacept is a fusion protein CTLA-4-IgG that acts like inhibitor molecules co stimulating $\mathrm{T}$ lymphocytes. Abatacept is indicated for patients with Rheumatoid Arthritis who had failed to DMARDS or anti TNF agents. It can be used isolated or associated to anti TNF. Abatacept is to be administered as an endovenous infusion over 30 minutes at a dose of $500 \mathrm{mg}$ in patients less than $60 \mathrm{~kg}, 750 \mathrm{mg}$ in patients between $60-100 \mathrm{~kg}$ and $1000 \mathrm{mg}$ in those with more than $100 \mathrm{~kg}$ body weight. The next dose should be administered two and four weeks after the initial dose and then every four weeks. The use of abatacept is associated with a higher incidence of infectious complications when compared to placebo, as observed with other biological DMARDs.

The infusion reactions with abatacept are uncommon and are mainly Hypersensitivity reactions manifested by rash or bronchospasm. It is contraindicated in patients with chronic obstructive pulmonary disease frame (COPD) due to exacerbation of dyspnoea and increased occurrence of infections [16].

According to the literature, the most common infusion reactions are: erythema, urticaria, eczema or a rash which may, in turn, be accompanied by pain or edema. 3 headache, nausea, dizziness. According to our observation, the most common infusional reactions were: higher of blood pressure, during the infusion, temporary bruise in the site of injection hypotermy, diarrhea, bradycardy. The incidence of site effects observed in our clinic was around 38 within 412 related cases. That corresponds to less than 10 percent of the total number of infusions. Concerning to gravity of the reactions, the majority of patients showed mild reactions.

Many doctors seem to fear the immunobiological drugs and their side effects. But, regarding to pre infusional anamnesis, low rate of infusion and follow up of the patient during the whole infusion, these drugs seem to be safe and with a low rate of side effects.

\section{References}

1. Megna M, Napolitano M, Balato N, Monfrecola G, Villani A, et al. (2016) Efficacy and safety of ustekinumab in a group of 22 elderly patients with psoriasis over a 2-year period. Clin Exp Dermatol 41(5): 564-566.
2. Shear NH, Hartmann M, Toledo-Bahena ME, Gilbert M, Katsambas A, et al. (2016) Health-related quality-of-life improvements during 98 weeks of infliximab therapy in patients with plaque-type psoriasis in real-world practice. Qual Life Res 25(8): 2031-2040.

3. Prinz JC, Puig L, Girolomoni G (2016) Treatment of psoriasis with etanercept: the typical patient profile. J Eur Acad Dermatol Venereol 30(7): 1092-1099.

4. Burness CB, McKeage K (2015) Adalimumab: A Review in Chronic Plaque Psoriasis. Drugs 75(18): 2119-2130.

5. Asahina A, Torii H, Ohtsuki M, Tokimoto T, Hase H, et al. (2016) Safety and efficacy of adalimumab treatment in Japanese patients with psoriasis: Results of SALSA study. J Dermatol 43(11): 1257-1266.

6. Stevenson M, Archer R, Tosh J, Simpson E, Everson-Hock E, et al. (2016) Adalimumab, etanercept, infliximab, certolizumab pegol, golimumab, tocilizumab and abatacept for the treatment of rheumatoid arthritis not previously treated with disease-modifying antirheumatic drugs and after the failure of conventional disease-modifying antirheumatic drugs only: systematic review and economic evaluation. Health Technol Assess 20(35): 1-610.

7. Kubo Y, Ohishi M, Nakashima Y, Okazaki K, Fukushi J, et al. (2015) Efficacy and Safety of Infliximab for Ankylosing Spondylitis in Japanese Patients: A Retrospective Study of 11 Cases. Fukuoka Igaku Zasshi 106(12): 316-322.

8. Bakshi J, Ismajli M, Rahman A (2015) New therapeutic avenues in SLE. Best Pract Res Clin Rheumatol 29(6): 794-809.

9. Kiely CJ, Subramaniam K, Platten J, Pavli (2016) Safe and effective: antitumour necrosis factor therapy use in pregnant patients with Crohn disease and ulcerative colitis. Intern Med J 46(5): 616-619.

10. Nagy G, Lukács K, Sziray A, Fazekas K, Florián A, Tamási L, et al. (2011) Adverse events during biological therapy -- focusing on dermatological side-effects Orv Hetil 152(6): 212-20.

11. Atzeni F, Gianturco L, Talotta R, Varisco V, Ditto MC, et al. (2015) Investigating the potential side effects of anti-TNF therapy for rheumatoid arthritis: cause for concern? Immunotherapy 7(4): 353361.

12. Trusson D, Pilnick A (2016) The Role of Hair Loss in Cancer Identity: Perceptions of Chemotherapy-Induced Alopecia Among Women Treated for Early-Stage Breast Cancer or Ductal Carcinoma in Situ. Cancer Nurs 40(2): E9-E16.

13. Moss IB, Moss MB, dos Reis DS, Coelho RM, et al. (2014) Immediate infusional reactions to intravenous immunobiological agents for the treatment of autoimmune diseases: experience of 2126 procedures in a non-oncologic infusion centre. Rev Bras Reumatol 54(2): 102-109.

14. Dika E, Patrizi A, Ribero S, Fanti PA, Starace M, et al. (2016) Hair and nail adverse events during treatment with target therapies for metastatic melanoma. Eur J Dermatol 26(3): 232-239.

15.Zintzaras E, Dahabreh IJ, Giannouli S, Voulgarelis M, Moutsopoulos $\mathrm{HM}$, et al. (2008) Infliximab and methotrexate in the treatment of rheumatoid arthritis: a systematic review and meta-analysis of dosage regimens. Clin Ther 30(11): 1939-1955.

16. Gaubitz M, Krüger K, Haas JP; Die Kommission Pharmakotherapie der DGRh (2014) Recommendations for use of abatacept in patients with rheumatoid arthritis. Z Rheumatol 73(10): 942-949. 


\section{Your next submission with Juniper Publishers} will reach you the below assets

- Quality Editorial service

- Swift Peer Review

- Reprints availability

- E-prints Service

- Manuscript Podcast for convenient understanding

- Global attainment for your research

- Manuscript accessibility in different formats

( Pdf, E-pub, Full Text, Audio)

- Unceasing customer service

Track the below URL for one-step submission https://juniperpublishers.com/online-submission.php 